based on the concept and measure on work engagement of their subordinate workers in Japan.

Methods The study sample was all managers and employees of a financial enterprise in Japan. The study design was a single-group pre-and post-test study. We developed a one-session 150 min workshop-based training program based on the HSE management competencies framework, including lectures, group works, and homework. Work engagement of subordinate workers was measured at baseline and 1 year follow-up by the short version of new Brief Job Stress Questionnaire (BJSQ). Improvement of 12 areas of sub-competencies among managers was also assessed by using the HSE competency indicator tool.

Results 94 managers (92 men and 2 women) and 1187 subordinate workers (590 men and 597 women) participated in the study. The scores of work engagement did not increase significantly from baseline to 1 year follow-up among subordinate workers as a whole, with a small effect size (Cohen's $\mathrm{d}=0.05$ ). However, multilevel analyses revealed that improvements of 6 sub-competency areas of managers was significantly associated with increase in work engagement of subordinate workers, particularly for the integrity $(\gamma=0.05, p=0.03$ for the crude analysis; $\gamma=0.05, p=0.03$ after adjusting for the covariates).

Conclusion The training program for managers failed to show its effect on improving work engagement of subordinate workers, possibly because of the low intensity of the program. However, it is suggested that the integrity might be a key management competency to improve work engagement of subordinate workers.

\section{RESIDENCY PROGRAM IN OCCUPATIONAL MEDICINE GUIDED BY THE COMPETENCES REQUIRED TO PRACTICE THE SPECIALTY IN BRAZIL}

DNP Della Torre*, EC Dias, JM da Silva. Hospital das Clínicas da Universidade Federal de Minas Gerais, Belo Horizonte, Brazil

\subsection{6/oemed-2018-ICOHabstracts.291}

Introduction The professional training in Occupational Medicine in Brazil is guided by the list of competences defined by the National Association of Occupational Medicine (ANAMT) in 2003 and updated in 2016, covering 6 domains and 28 essential competencies headed by the competence of moral judgment. This work presents the results of a study carried out with the objective of elaborating a residency program in Occupational Medicine at the Hospital das Clínicas of the Federal University of Minas Gerais, with a duration of 2 years, distributed in 5760 hours, with emphasis on detailing the essential competences of the Professionalism and Study and Intervention on the Health Situation of Workers.

Methods The quantitative-qualitative study took as reference the competences defined by ANAMT and the norms that regulate the medical residency programs in the country, with the construction of matrices that were successively submitted to the appreciation of residents, graduates of the program and professionals specialised in the area. At the end, a Seminar was held to validate the results.

Result A preliminary document was produced where the main technical knowledge, skills and attitudes expected for each general competence contained in the fields of Professionalism and Study and Intervention on the Health Situation of Workers were defined and listed.

Discussion This study detailed the general competences of the first two domains of the competency matrix prepared in 2016 by ANAMT with the aim of making their use easy and practical. This detail can serve as a platform for the development and orientation of Medical Residency Programs in Occupational Medicine.

\section{VIOLENCE AGAINST STUDENT NURSES BY PATIENTS AND THEIR RELATIVES IN PUBLIC HOSPITALS IN KWAZULU-NATAL, SOUTH AFRICA}

1,2Bongi Majola, ${ }^{1}$ Penny Orton*, 'Ayisha Razak. 'Durban University of Technology, Durban, South Africa; ${ }^{2}$ KwaZulu Natal College of Nursing, Durban, South Africa

\subsection{6/oemed-2018-ICOHabstracts.292}

Introduction Workplace violence in the healthcare setting is increasing and poses a danger to healthcare professionals. It is reported that nurses are at three times greater risk of being exposed to violence in the workplace than any other professional group.

Methods A quantitative, descriptive, cross-sectional survey was conducted at four randomly selected campuses of the KwaZulu Natal College of Nursing. A non-probability convenience sample of 421 student nurses was realised. A validated and reliable instrument was used to collect data which was statistically analysed using SPSS 23. Tests included Pearson's correlation, t-tests, Anova and chi-square.

Result Majority of those sampled were female and Black with more female victims of workplace violence than males. Male patients and their relatives were most often the perpetrators. Male students reported depression and negative effects on personal relationships more often than females. Males felt that it was not important for them to report any workplace violence and more males saw it as part of the job.

The wards were the most likely site to experience violence with the operating theatres the least likely.

The senior students reported more abuse in the workplace than the junior students. There were no significant relationships between the year of study and reporting of violence and the awareness of any policy in the hospital addressing workplace violence.

Violence in the workplace was not, for the majority of those sampled, a reason to consider leaving the profession.

Discussion Student nurses are victims of workplace violence, perpetrated by patients and their relatives, in the public hospitals of KZN. They call in absent at work and feel angry and depressed. Many of these victims do not report the incidences of abuse that take place during their clinical placement and many are not even aware of the policies that exist in their institutions.

\section{ASYNCHRONOUS, ONLINE TRAINING OF HEALTHCARE WORKERS AND HYGIENE/SAFETY MANAGERS IN OCCUPATIONAL HEALTH AND HYGIENE}

${ }^{1}$ Linda Forst* ${ }^{*}$ 1,2Leslie Nickels, ${ }^{1,3}$ David Zalk, ${ }^{1} J o s e p h$ Zanoni. 'University of Illinois at Chicago School of Public Health; ${ }^{2}$ National Institute for Occupational Safety and Health; ${ }^{3}$ Lawrence Livermore Laboratories

10.1136/oemed-2018-ICOHabstracts.293 